\title{
Mathematical model of stacked one-sided arrangement of the burners
}

\author{
J.A. Oraz ${ }^{1, *}, I$. E Korzilova ${ }^{1}, A$. N. Ermolaev ${ }^{2}$, S.A. Khaustov ${ }^{1}$, and $A$.Y. Dolgih ${ }^{1}$ \\ ${ }^{1}$ National Research Tomsk Polytechnic University, 634050 Tomsk, Russia \\ ${ }^{2}$ Federal State budget institution of higher education "Tyumen industrial University", 625000 \\ Tyumen, Russia
}

\begin{abstract}
Paper is aimed at computer simulation of the turbulent methane-air combustion in upgraded U-shaped boiler unit. To reduce the temperature in the flame and hence NOx release every burner output was reduced, but the number of the burners was increased. The subject of studying: complex of characteristics with space-time fields in the upgraded steam boiler E-370 with natural circulation. The flare structure, temperature and concentrations were determined computationally.
\end{abstract}

\section{Introduction}

The power industry of the country is one of the key industries. Energy balance directly effects on the economic welfare of the state. Currently, the Russian power industry is experiencing a moral and technological crisis. One of the main problems is outdated equipment. According to experts [1-4] up to $80 \%$ of boilers and turbines are exhausted their resources. To replace existing power plants is necessary to design new equipment with modern technologies, taking into account the operating experience of the analogical power systems $[4,5]$.

The object of research is the boiler unit is a U-shaped layout with natural circulation for the combustion of natural gas with superheated steam capacity of $370 \mathrm{t} / \mathrm{h}$. The subject of research are the basic geometrical characteristics of the steam boiler with natural circulation. Full-scale multiple-factor experimental research of described three-dimensional vortical turbulent combustion is quite expensive. Therefore, nowadays computer simulation with the use of wide approved application packages is used to research furnace aerodynamics $[6,7]$. For example, burning turbulent flow was simulated in [5-7].

Modern computer technology makes simulation of the boiler unit operation possible even during the development. Computer experiment allows to study the processes of heat and mass transfer, combustion and aerodynamics. The results reveal the shortcomings of the developed design, predict the operation of the boiler unit, check the possibility of nonproject fuel combustion. Using mathematical modeling the economic costs associated with the construction are minimized.

* Corresponding author: zhanibek.oraz@gmail.com 
To date, one of the most powerful software products for mathematical modeling is software package ANSYS FLUENT [4, 6, 7]. This software module allows solving the problem of hydro and gas dynamics, taking into account the turbulence, heat transfer and chemical reactions.

\section{The method of research and the initial data}

Construction of the main elements of the boiler was performed in accordance with the experience of similar boilers designing. The sequence of calculation, construction of heating surfaces of the boiler layout selection, the combustion chamber and burners made in accordance with regulatory guidelines.
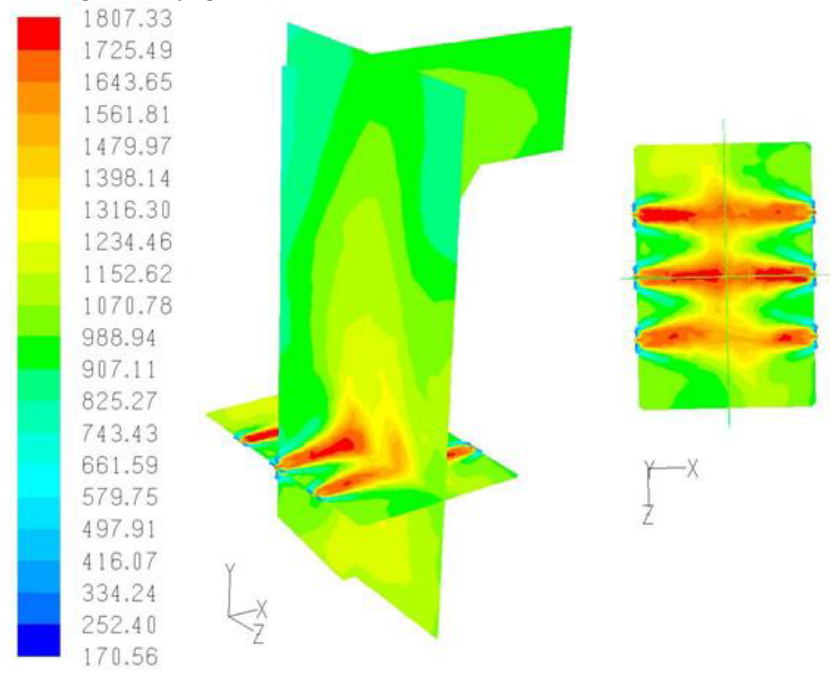

Fig. 1. The temperature distribution of the combustion medium $\left({ }^{\circ} \mathrm{C}\right)$ before modernization.

To identify gaps in the developed design and predict the various boiler unit loads mathematical modeling of thermal processes in the combustion chamber of the boiler E-370 was made using FLUENT software package. Methods of modeling and mathematical models used are given in $[4,6,7]$. It is established that there is a large flare temperature, causing the high intensity of the generating of the nitrogen oxides and other harmful substances.

Table 1. Initial parameters.

\begin{tabular}{|c|c|c|c|c|c|c|}
\hline \multirow{2}{*}{\multicolumn{2}{|c|}{ Initial parameter }} & \multirow{3}{*}{$\begin{array}{l}\text { unit } \\
\mathrm{mm}\end{array}$} & \multicolumn{4}{|c|}{ Elements of the horizontal gas duct } \\
\hline & & & \multirow{2}{*}{$\frac{\mathrm{SH} 2}{32 \times 4}$} & \multirow{2}{*}{$\frac{\mathrm{SP}}{133 \times 13}$} & \multirow{2}{*}{$\begin{array}{c}\mathrm{SH} 3 \\
32 \times 4\end{array}$} & \multirow{2}{*}{$\begin{array}{c}\text { SH1 } \\
32 \times 4\end{array}$} \\
\hline pipe diameter & $\mathrm{d}$ & & & & & \\
\hline pipe arrangement & - & - & \multicolumn{4}{|c|}{ row arrangement } \\
\hline \multirow{2}{*}{ pipe pitch } & $\mathrm{S}_{1}$ & \multirow{2}{*}{$\mathrm{mm} / \mathrm{mm}$} & 530 & 0.74 & 100 & 80 \\
\hline & $\overline{S_{2}}$ & & $\overline{48}$ & $\overline{-}$ & $\overline{140}$ & $\overline{120}$ \\
\hline \multirow{2}{*}{ relative pipe pitch } & $\underline{\sigma_{1}}$ & \multirow{2}{*}{-} & 16.56 & 5.56 & 3.125 & 2.5 \\
\hline & $\overline{\sigma_{2}}$ & & $\overline{1.5}$ & $\overline{-}$ & $\overline{1.5625}$ & $\overline{1.5625}$ \\
\hline number of entries & $\mathrm{n}$ & - & 2 & 1 & 1 & 1 \\
\hline heating surface & $\mathrm{H}$ & $\mathrm{m}^{2}$ & 455.429 & 39.375 & 1606.164 & 890.21 \\
\hline
\end{tabular}

Turbulent combustion of natural gas in the reverse flame of fire-tube boiler was studied by means of the ANSYS Fluent 12.1.4 engineering simulation software. The following 
processes were simulated through the finite-element method: chemical reactions, turbulence, and heat exchange. The gas-phase was simulated according to the the NavierStokes differential equations in Euler's approximation. Aerodynamic calculations were performed using the differential equations of flow continuity and energy conservation. The radiant heat exchange calculation was conducted by the differential equations of spherical harmonics in first approximation (P1-model).

\subsection{Modernization project}

As a result of this work it has been upgraded E-370 boiler capacity of $260 \mathrm{MW}$ with an estimated fuel consumption of $6.4 \mathrm{~m}^{3} / \mathrm{s}$ and a gross efficiency of $94.6 \%$. According to the adopted in the design of the combustion chamber of the boiler is not cold funnel, instead of it is designed for sloping (Fig. 2). On the front wall of the furnace are nine combination gas-oil burners in three levels.
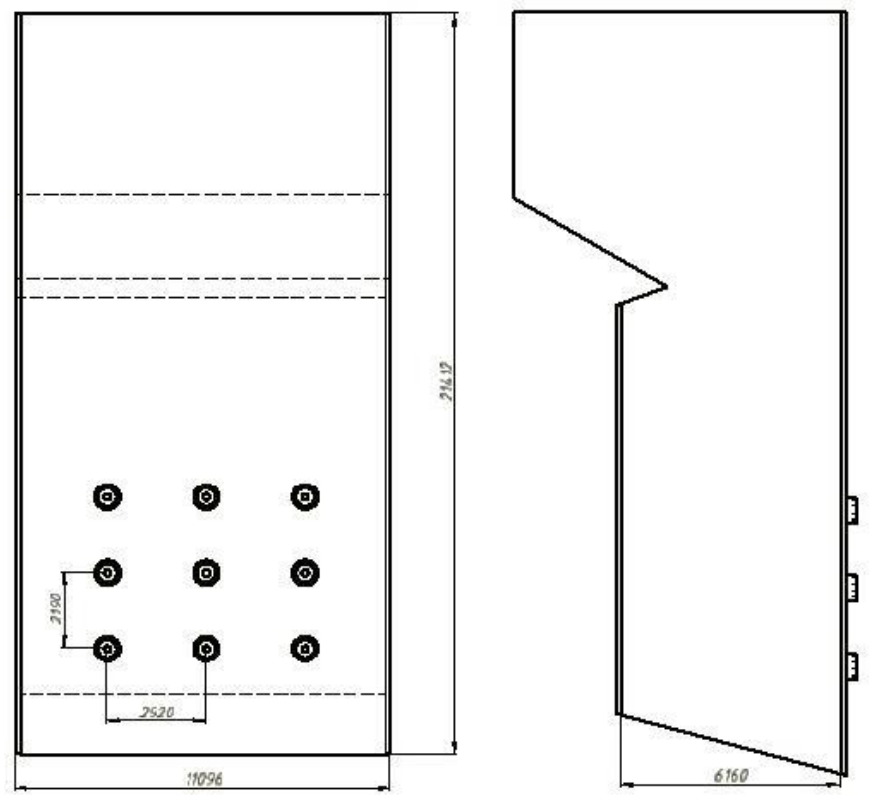

Fig. 2. Sketch of the upgraded furnace.

In the upgraded boiler burner output is reduced, but the number of the burners is increased (fig. 2). This technical solution allows to increase the efficiency of the boiler unit and to achieve the required temperature of exhaust gases.

Upgraded radiative-convective superheater has a four-stage steam superheating and executed by a mixed scheme. Two-step regulation of the superheated steam is applied using the temperature of its own condensate injection. The convective part consists of singlestage water economizer and recuperative air heater.

\subsection{Initial data for mathematical modelling}

Using computer-aided design three-dimensional model of the computational domain for modeling was built and converted to the tetragonal computational mesh (Fig. 3a) with its further transformation into a polyhedral mesh (Fig. 3b). As a result of the transformation the number of cells is declined, but the number of computational nodes is increased 
(Table 2). These allow to increase the convergence and accuracy of the numerical simulation, as well as time of the calculation.

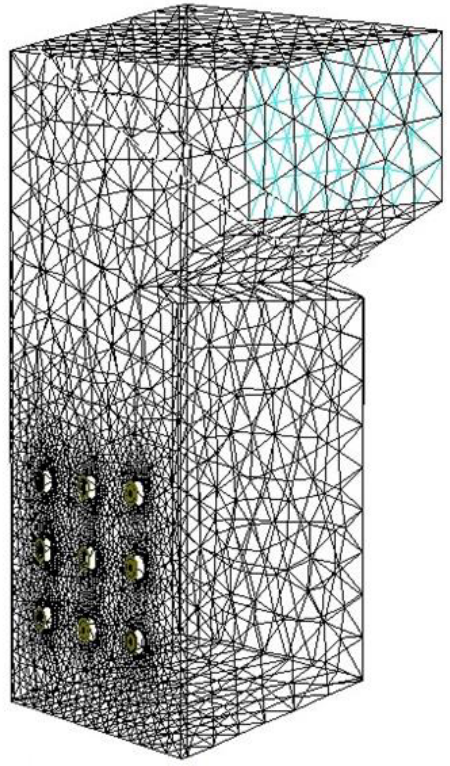

(a)

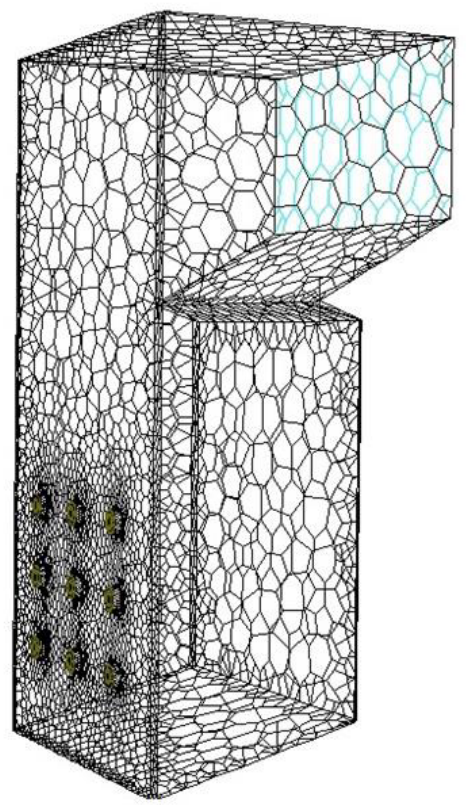

(b)

Fig. 3. Computational mesh for mathematical modeling : a) tetrahedral; b) polyhedral.

Table 2. Computational mesh features.

\begin{tabular}{|c|c|c|}
\hline Mesh type & Nodes & Cells \\
\hline Tetrahedral & 237033 & 22288 \\
\hline polyhedral & 213942 & 159388 \\
\hline
\end{tabular}

\section{Calculation results}

One of the most important thermal characteristics of the boiler unit is the temperature of the heating medium (Fig. 1). Quantitative assessment of this indicator will set the heat absorption of each of the heating surface, consequently, to assess the reliability of the boiler.

Chart shows the changes of the flare temperature (fig. 5). The main steam superheating occurs in the platen heating surface. Decrease coolant temperature (jumps on the chart) due to the presence of its own condensate injection. Lowering the temperature of steam ensures the reliability of the superheater. Just before injection SHII and SH3 makes possible, if necessary, the coolant temperature control before being fed to the consumer.

To avoid possible overheating of the walls of furnace tubes of metal was analyzed long range burners. According to the results of analysis of the burner have been designed so that combustion of the core housed in the center of the combustion chamber (Fig. 5), except flame impingement on the screen panel, thereby preventing the burnout of pipes and ensuring combustion stability. 


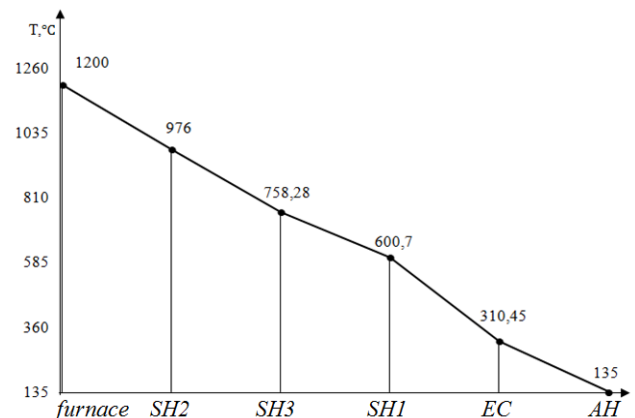

(a)

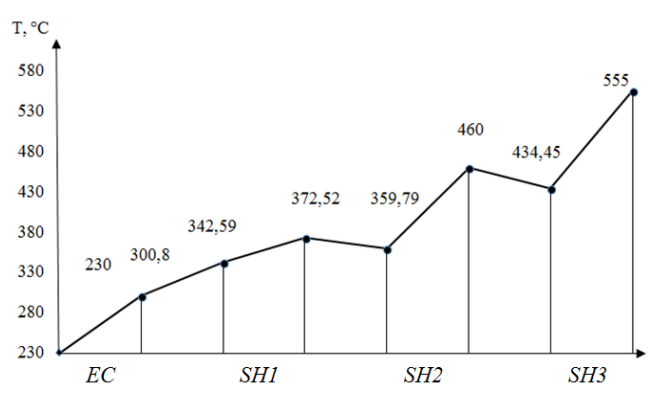

(b)

Fig. 4. Flue gas (a) and steam (b)temperature: $\mathrm{SH}$-superheater, EC - economizer, $\mathrm{AH}$ - air heater.

Ensuring the environmental safety of the area of installation requires calculation of emissions. It is well known fact that natural gas combustion has large heat observed (Fig. 5) in the combustion nucleus [8]. In connection with that the problems associated with an increasing in emissions of nitrogen oxides are expected.

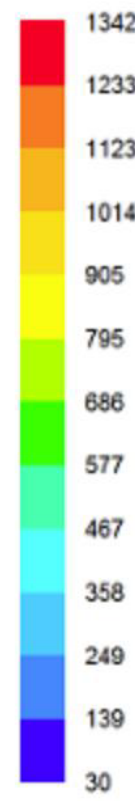

Fig. 5. temperature isolines in cross sections of the combustion chamber $\left({ }^{\circ} \mathrm{C}\right)$.

\section{Conclusion}

In this paper, the numerical simulation of turbulent combustion of natural gas in large power ramjet burner was used to study the processes occurring in the combustion chamber. According to the results of numerical modelling it can be concluded that the selected arrangement of the multilevel burners reduces emissions of nitrogen oxides (fig. 6). The furnace outlet $\mathrm{NO}_{\mathrm{x}}$ amount does not exceed the permissible value of $100 \mathrm{mg} / \mathrm{m}^{3}$. There is a pronounced vortex aerodynamics in the furnace, which contribute to a sharp increase in the residence time of the fuel and oxidizer near the burner, and promotes intensive ignition and fuel burnup. 

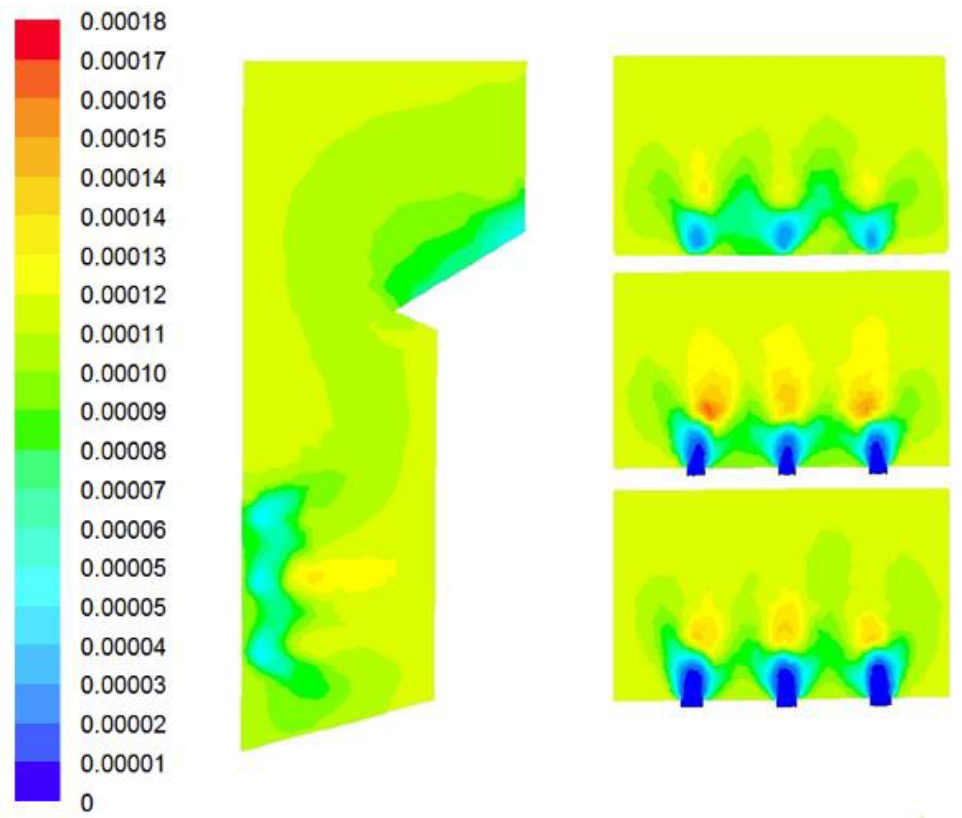

Fig. 6. Contour plot of the total $\mathrm{NO}_{\mathrm{x}}$ mass fraction.

The upgraded boiler is a worthy replacement for the outdated boilers. The results obtained during the computational experiment, suggest that engineered boiler unit is designed in accordance with modern standards and regulations. These results confirm the effective of the modeling techniques for designing the boiler equipment.

The reported study was partially supported by the Ministry of education and science of The Russian Federation, state order No. 13.948.2014/K.

\section{References}

1. Z. Arsenijević, Z. Grbavčić, B. Grbić, N. Radić, R. Garić-Grulović, S. Miletić, G. Savčić, B. Dordević, J. Serb. Chem. Soc. 75, 523 (2010)

2. K.A. Al-attab, J.C. Ho, Z.A. Zainal, Exp. Therm. Fluid Sci. 62, 1 (2015)

3. X.-R. Chen, X.-S. Li, Z.-Y. Chen, Y. Zhang, K.-F. Yan, Q.-N. Lv, Energies 8, 1242 (2015)

4. S. Dolgov, E. Savchenko, S. Khaustov, R. Tabakaev, A. Zavorin, EPJ Web of Conf. 110, 01074 (2016)

5. S. A. Khaustov, A. V. Kazakov, G. A. Cherkashina, L. A. Sobinova, EPJ Web of Conf. 110, $01028(2016)$

6. A. V. Kazakov, S. A. Khaustov, R. B. Tabakaev and Y. A. Belousova, IOP Conf. Series: Mater. Sci. Eng. 124, 012110 (2016)

7. S. A. Khaustov, A. S. Zavorin, K. V. Buvakov, L. D. Kudryashova, A. V. Tshelkunova, EPJ Web Conf. 82, 1041 (2015) 